\title{
Analisis Kepuasan Nasabah Pada PT. Bank Tabungan Negara (persero) Tbk. Kantor Cabang Syariah Yogyakarta
}

\section{Aidha Trisanty *}

\begin{abstract}
Complex competition in syaria' banking industries requires each player in that sector to sharp strategy in onder to win the rivalry, particulary on how to satisfy their customer. This study intends to investigate customer satisfaction in BTN syariah Yogyakarta using six elements spesifically compliance, assurance, reliability, tangible, empathy and responsiveness.

The result shows that the custumers satisfy only on two dimensions explicitly compliance and dimension while in four other aspects (reliability, tangibles, empathy and responsiveness) they feel unsatify. It means that there is a negative gap between service quality that BTN given and their customers perception.
\end{abstract}

Keywords : Customer satisfaction, compliance,assurance, reliability, tangible, empathy and responsiveness. 


\section{Pendahuluan}

Industri Perbankan Syariah di Indonesia beberapa tahun terakhir ini mengalami perkembangan yang cukup pesat. Diawali dengan adanya Undang - Undang No. 10 tahun 1998 tentang Perbankan yang mengatur secara rinci landasan hukum serta jenis - jenis usaha yang dapat diimplementasikan oleh Bank Syariah, ditambah dengan adanya berbagai kebijakan dan regulasi dari Bank Indonesia dan fatwa dari MUI tentang haramnya bunga bank, semakin mendorong pertumbuhan Perbankan Syariah di Indonesia. Salah satu perkembangan tersebut ditunjukkan dengan terus bertambahnya jumlah Bank Syariah di Indonesia dari tahun ke tahun, dimana saat ini sebelas Bank Umum Syariah dan dua puluh empatUnit Usaha Syariah dari Bank Konvensional telah berdiri di Indonesia.

Terus bertambahnya jumlah Perbankan Syariah,ditambah lagi dengan keberadaan Perbankan Konvensional yang lebih dulu ada dengan pangsa pasarnya yang masih sangat mendominasi, tentunya menyebabkan makin kompleksnya persaingan yang dihadapi oleh setiap Bank Syariah. Hal ini menyebabkan para pemain di bisnis Perbankan Syariah dituntut untuk terus mencari cara dan langkah - langkah agar terus dapat bertahan dan memenangkan persaingan.

Bank BTN Kantor Cabang Syariah Yogyakarta (BTN KCS Yogyakarta), sebagai salah satu bank yang beroperasi di wilayah DI Yogyakarta, merupakan cabang:dari Unit Usaha Syariah dari PT. Bank Tabungan Negara (Persero) Tbk yang pendiriannya tergolong baru bila dibandingkan dengan Perbankan Syariah lainnya di Yogyakarta.Keberadaannya yang belum genap satu dasawarsa ditambah jumlah kantor layanan yang masih terbatas dibandingkan perbankan lain 
yang menjadi kompetitornya tentunya menjadi tantangan tersendiri dalam mengembangkan bisnis dan memenangkan persaingan.

Salah satu strategi yang dapat dilakukan agar sukses dalam bisnis jasa ini menurut Thompson, De Souza dan Gale (1985) adalah delivery of high service (pemberian layanan yang berkualitas atau kualitas layanan yang baik). Kualitas layanan menurut Kotler (1987) dalam Kuntoro Harjo dan Asri Laksmi Riani (2003: 123) merupakansuatu bentuk penilaian konsumen terhadap tingkat. layanan yang diterima (perceivedservices) dengan tingkat pelayanan yang diharapkan (expected services), dimana layanan dapat disebut berkualitas dan memuaskan apabila produk atau jasa tersebut telah memenuhi atau bahkanmelampaui harapan konsumen.Kualitas layanan tersebut dapat dilihat melalui dimensi assurance (kemampuan memberikan jaminan layanan), reliability (kemampuan untuk memberikan layanan yang telah dijanjikan secara akurat, dapat dipercaya, dan diandalkan), tangibles (fasilitas yang ditawarkan dalam bentuk fisik), empathy (kemampuan perusahaan dalam memahami keinginan konsumen), dan responsiveness (kesigapan dalam merespon layanan yang dibutuhkan). Disamping kelima dimensi tersebut, untuk Perbankan Syariah yang memiliki karakteristik khusus, maka terdapat satu dimensi tambahan yaitu compliance atau kepatuhan terhadap unsur syariah (Othman dan Owen, 2011).

Dengan tantangan yang dihadapi oleh BTN KCS Yogyakarta tersebut, maka kualitas pelayanan kepada nasabah perlu menjadi prioritas utama, dimana perusahaan harus mampu memenuhi keinginan dan harapan nasabah agar nasabah puas. Kepuasan tersebut tentunya berdampak positif bagi perusahaan karena dapat meningkatkan loyalitas nasabah yang pada akhirnya akan membantu perusahaan untuk bertahan 
dan mẹmenangkan persaingan. Melalui penelitian. ini, BTN KCS Yogyakarta dapat mengetahui bagaimana harapan atau keinginan nasabah dilihat dari dimensi kualitas layanan yang ada serta mengetahui bagaimana tingkat kepuasan nasabah terhadap layanan yang telah diberikan sehingga dapat menjadi masukan bagi manajemen dalam menentukan strategi yang akan dilaksanakan.

\section{Kajian Pustaka}

Osman, dkk (2009), melakukan penelitian terhadap kepuasan nasabah pada Malaysian Islamic Banking dengan menggunakan metode CARTER. Penelitian tersebut menunjukkan hasil bahwa dimensi Reliability (mean 5.05) adalah faktor yang dianggap paling penting dalam memilih lembaga keuangan Islam. Sedangkan dimensi berikutnya adalah Assurance, Tangibles dan kemudian diikuti oleh dimensi Empathy, Responsiveness dan Compliance.

Penelitian tentang kualitas layanan di BTN Syariah Yogyakarta sebelumnya pernah dilakukan oleh Arika Edi Mulyanto, dimana hasil penelitian tersebut menunjukkan bahwa kualitas pelayanan BTN Syariah Cabang Yogyakarta berdasarkan dimensi Reliability (4,03), Assurance $(4,05)$ dan Emphaty $(4,16)$, dinilai sudah sangat baik sedangkan dimensi Tangibles $(3,81)$ dan Responsiveness $(3,90)$ baru dinilai baik. 


\section{Landasan Teori}

\section{Dimensi Kualitas Layanan Jasa}

Parasuraman et al (1991) mendefinisikan kualitas layanan sebagai suatu evaluasi atau penilaian secara keseluruhan mengenai kualitas barang dan jasa. Kualitas merupakan fungsi gap antara harapan konsumen terhadap layanan dan persepsi mereka terhadap layanan aktual yang diterima, yang dirumuskan sebagai berikut :

\section{Persepsi - Harapan $=$ Gap}

1) Jika gap positif (persepsi > harapan), maka kualitas layanan dapat dikatakan sangat memuaskan.

2) Jika gap nol (persepsi = harapan), maka kualitas layanan dapat dikatakan memuaskan.

3) Jika gap negatif (persepsi < harapan), maka kualitas layanan dikatakan tidak memuaskan.

Parasuraman, dkk (dalam International Journal of Islamic Financial Services Vol. 3. No. 1) melakukan penelitian khusus terhadap beberapa jenis jasa, dan berhasil mengidentifikasi sepuluh dimensi utama yang menentukan kualitas jasa, yang kemudian disederhanakan menjadi lima dimensi, yaitu :

1) Tangibles (bukti fisik), yaitu ditunjukkan dengan tampilan gedung, fasilitas fisik pendukung, perlengkapan dan penampilan karyawan.

2) Reliability (keandalan), yaitu kemampuan penyedia layanan memberikan layanan yang dijanjikan dengan segera, tepat dan akurat.

3) Responsiveness (daya tanggap), yaitu kemauan dan kesediaan karyawan untuk membantu pelanggan serta memberikan layanan yang baik. 
4) Assurance (jaminan), yaitu pengetahuan dan kecakapan para karyawan yang memberikan jaminan bahwa mereka dapat melayani dengan baik dan menumbuhkan rasa percaya pelanggan pada perusahaan.

5) Emphaty (empati), yaitu kemampuan karyawan dalam memahami kebutuhan pelanggan dengan memberikan perhatian secara individual.

Untuk perusahaan yang memiliki karakteristik khusus seperti pada perbankan syariah, maka selain lima dimensi diatas, dilakukan modifikasi dengan menambahkan dimensi Compliance, berupa prinsip dan hukum Islam, seperti yang dikembangkan oleh Othman dan Owen (2011). Dengan penambahan dimensi tersebut maka kualitas layanan pada perbankan syariah terdiri dari enam dimensi yang disebut dengan metode CARTER (compliance, assurance, reliability, tangibles, emphaty dan responsiveness).

\section{Kepuasan Pelanggan}

Kepuasan merupakan salah satu keunggulan kompetitif yang harus diwujudkan perusahaan dalam upaya untuk mempertahankan pelanggan. Kotler dan Armstrong dalam Bangun Kuntoro Harjo dan Asri Laksmi Riani (2003:128), mendefinisikan kepuasan pelanggan adalah perasaan senang atau kecewa seseorang setelah membandingkan kinerja (hasil) yang dia rasakan dengan harapannya. Sedangkan Menurut Engel dalam Fandy Tjiptono, (2000:146) menyatakanbahwa kepuasan pelanggan merupakan evaluasi purnabeli dimana alternatifyang dipilih sekurangkurangnya memberikan hasil sama atau melampauiharapan pelanggan, sedang ketidakpuasan timbul bila hasil yang diperoleh tidak sesuai dengan harapan. 
Kepuasan yang dirasakan konsumen akan menyebabkan konsumen melakukan pembelian secara berulang (loyal). Kondisi ini memberikan keuntungan bagi perusahaan, antara lain ; mengurangi biaya pemasaran, mengurangi biaya transaksi, mengurangi biaya turn - over pelanggan, meningkatkan penjualan silang yang akan meningkatkan pangsa pasar perusahaan, Word of Mouth yang lebih positif dan mengurangi biaya kegagalan. Disamping itu, pelanggan yang puas dengan produk yang dikonsumsinya akan memberikan keuntungan bagi perusahaan diantaranya menjadikan pelanggan lebih setia, tidak terlalu sensitif terhadap harga, menolak produk lain, dan memberikan komentar yang menguntungkan bagi perusahaan.

\section{Metode Penelitian}

\section{Populasi dan Sampel}

Populasi dari penelitian ini adalah seluruh nasabah BTN KCS $\approx=$ Yogyakarta baik yang ada $\approx$ di kantor cabang maupun kantor cabang pembantu. Sampel dipilih dengan menggunakan metode convenience sampling, dimana sampel diperoleh dari elemen populasi yang datanya mudah diperoleh (Supomo dan Indrianto, 1999).

Pengumpulan data dilakukan melalui penyebaran kuesioner kepada responden dengan menggunakan skala likert yang mempunyai gradasi dari sangat tidak setuju sampai sangat setuju.Sedangkan instrumen untuk mengukur kepuasan nasabah adalah dengan menggunakan metode CARTER. 


\section{Kerangka Kerja}

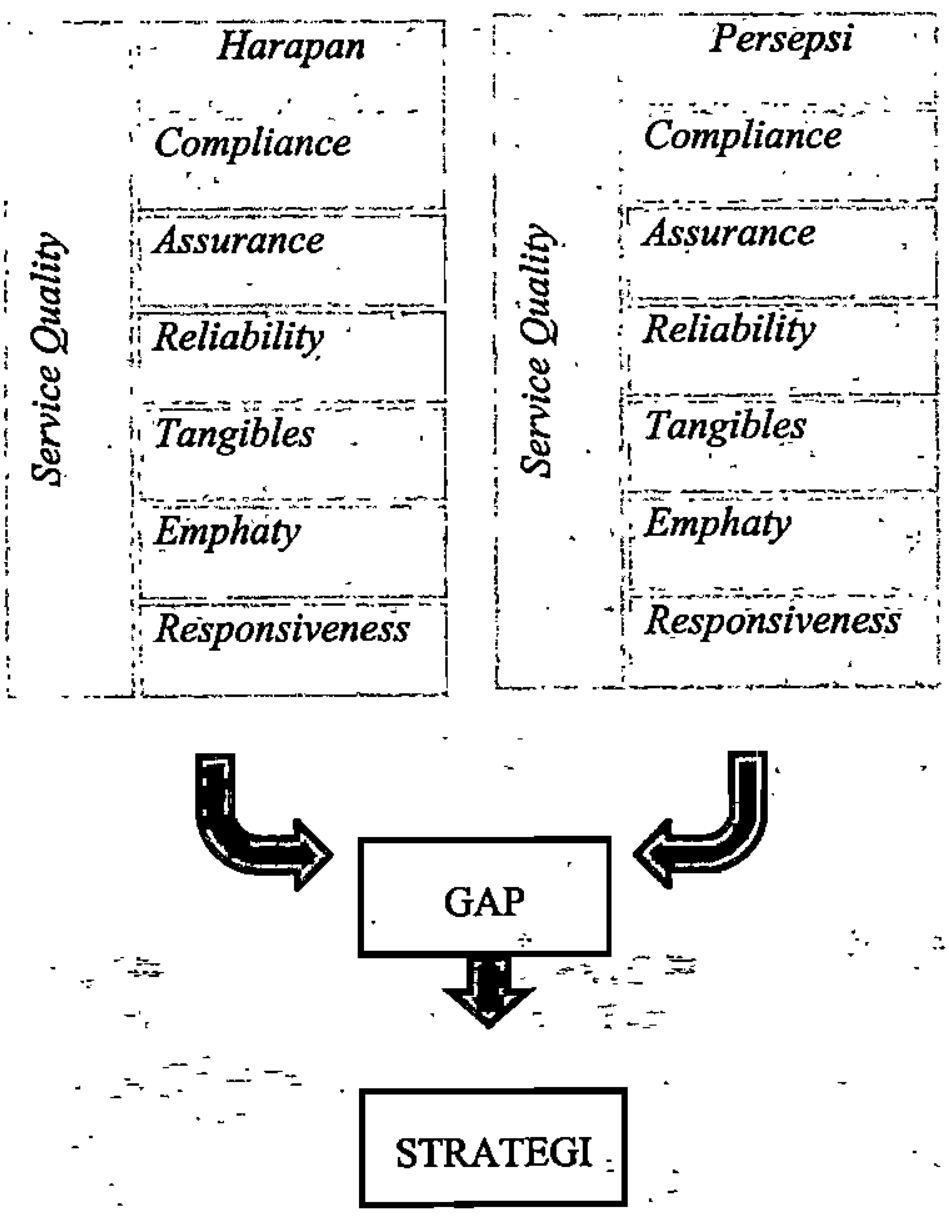

Mètode Analisis Data

\section{Uji Validitas}

Validitas adalah suatu ukuran yang menunjukkan seberapa jauh alat ukur tersebut bisa mengukur apa yang seharusnya diukur. (J. Supranto, 2001 :107). Uji ini digunakan untuk mengukur valid atau tidaknya suatu kuesioner. 


\section{Uji Reliabilitas}

Uji reliabilitas adalah sejauh mana hasil suatu pengukuran dapat dipercaya. Suatu kuesioner dikatakan reliabel atau handal jika jawaban seseorang terhadap pertanyaan adalah konsisten atau stabil dari waktu ke waktu.

\section{Analisis Servqual}

Servqual berasal dari kata Service Quality yang artinya kualitas layanan. Metode ini didasarkan pada Gap Model yang dikembangkan oleh Parasuraman, et al (1994). Kualitas layanan merupakan fungsi gap antara harapan konsumen terhadap layanan dengan persepsi mereka terhadap layanan aktual yang dihasilkan. Atau dengan kata lain, kualitas layanan merupakan selisih antaralayanan yang dirasakan konsumen dan layanan yang diinginkan konsumen.

\section{Diagram Cartesius}

Merupakan suatu bangunan yang terdiri dari empat bagian yang dibatasioleh dua garis tegak lurus pada titik $\mathrm{X}$ danY. $\mathrm{X}$ merupakan rata - rata dari skor penilaian kinerja/tingkat kepuasan dan $\mathrm{Y}$ adalah rata-rata skor tingkat kepentingan/harapan.

\section{Hasildan Pembahasan}

Dari hasil uji tabel validitas menunjukkan bahwa seluruh item pertanyaan didalam kuesioner untuk variabel penelitian adalah valid. Semua indikator yang digunakan untukmengukur variabel-variabel yang digunakan dalam penelitian ini memilikikoefisien korelasi yang lebih besar dari $r$ tabel. Dalam hal ini rbtyang terkecil adalah pada pertanyaan I.4 sebesar 0.3889 sedangkan $r$ tabel adalah 0.2407 . 
Hasil uji reliabilitas menunjukkan semua alpha lebih besar dari 0,60. Sehingga dapatdikatakan bahwa seluruh variabel pertanyaan dalam kuesioner ini adalah reliabel sehingga data yangdihasilkan dapat dianalisis lebih lanjut.

\section{Gap Persepsi dan Harapan}

Tabel 1 : Gap Penilaian Persepsi dan Harapan terhadap Kualitas Layanan NasabahBTN KCS Yogyakarta (per Dimensi)

\begin{tabular}{|c|l|l|l|l|l|l|}
\hline No & \multicolumn{1}{|c|}{ Dimensi } & Harapan & Persepsi & Gap & \multicolumn{1}{|c|}{ Nilai } & \multicolumn{1}{|c|}{ Ket } \\
\hline 1 & Compliance & 4.170 & 4.172 & Positif & 0.002 & Sangat Puas \\
\hline 2 & Assurance & 4.270 & 4.512 & Positif & 0.242 & Sangat Puas \\
\hline 3 & Reliability & 4.360 & 4.326 & Negatif & 0.034 & Tidak Puas \\
\hline 4 & Tangibles & 4.364 & 4.310 & Negatif & 0.054 & Tidak Puas \\
\hline 5 & Emphaty & 4.292 & 4.224 & Negatif & 0.068 & Tidak Puas \\
\hline 6 & Responsiveness & 4.314 & 4.228 & Negatif & 0.086 & Tidak Puas \\
\hline Jumlah & 25.77 & 25.772 & Positif & $\mathbf{0 . 0 0 2}$ & SANGAT PUAS \\
\hline \multicolumn{2}{|l|}{ Rata - Rata } & 4.2950 & 4.2953 & Positif & $\mathbf{0 . 0 0 0 3}$ & SANGAT PUAS \\
\hline
\end{tabular}

Dari enam dimensi kualitas layanan yang ada konsumen baru merasa puas terhadap dimensi compliance dan dimensi assurance. Sedangkan untuk empat dimensi lainnya, yaitu reliability, tangibles, emphaty dan responsiveness konsumen belum merasa puas, hal ini ditunjukkan dengan gap yang masih negatif. Namun secara keseluruhan, penilaian konsumen terhadap kualitas layanan BTN KCS Yogyakarta sudah memuaskan. 


\section{Tabel 2 : Gap Penilaian Persepsi dan Harapan terhadap Kualitas Layanan NasabahBTN KCS Yogyakarta (per Atribut)}

\begin{tabular}{|c|c|c|c|c|c|c|}
\hline Dimensi & Pertanyaan & $\begin{array}{l}\text { Harap } \\
\text { gn }\end{array}$ & $\begin{array}{l}\text { Persep } \\
\text { si }\end{array}$ & Gap & Nilai & $\begin{array}{l}\text { Keteranga } \\
\quad \mathbf{n}\end{array}$ \\
\hline \multirow{5}{*}{ 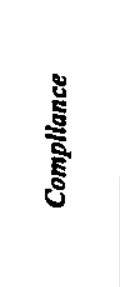 } & 1. Prinsip dan hukum Islam & 4.06 & 4.54 & Positif & 0,48 & Puas \\
\hline & $\begin{array}{l}\text { 2. Tidak ada pembayaran bunga } \\
\text { tabungan }\end{array}$ & 4.11 & 4.25 & Positif & 0,14 & Puas \\
\hline & $\begin{array}{l}\text { Memberikan pembiayaan pada produk } \\
\text { yang halal }\end{array}$ & 4.28 & 4.41 & Positif & 0,13 & Puas \\
\hline & $\begin{array}{l}\text { 4. Menerapkan ketentuan bebas bunga } \\
\text { pinjaman }\end{array}$ & 4.06 & 3.92 & Negatif & 0,14 & Tidak Puas \\
\hline & 5. Tidak meminta agunan pada nasabah & 4.34 & 3.74 & Negatif & 0,60 & Tidak Puas \\
\hline \multirow{5}{*}{ 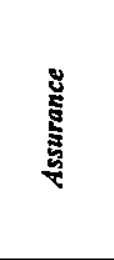 } & 6. Memiliki reputasi dan nama baik & 4.00 & 4.51 & Positif & 0,51 & Puas \\
\hline & $\begin{array}{l}\text { 7. Manajenen nemiliki pengalaman dan } \\
\text { pengetahuan Iuas }\end{array}$ & 4.48 & 4.37 & Negatif & 0,11 & Tidak Puas \\
\hline & 8. Karyawan sopan dan bersahabat & 4.32 & 4.66 & Positif & 0,34 & Puas \\
\hline & 9. Ketersediaan likuiditas & 4.26 & 4.50 & Positif & 0,24 & Puas \\
\hline & 10. Tersedia tenaga keamanan & 4.29 & 4.52 & Positif & 0,23 & Puas \\
\hline \multirow{5}{*}{ 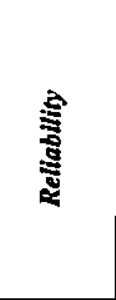 } & 11. Memberikan layanan yang tepat & 4.33 & 4.46 & Positif & 0,13 & Puas \\
\hline & 12. Produk dan layanan beragam & 4.42 & 4.3 & Negatif & 0,12 & Tidak Puas \\
\hline & 13. Layanan cepat dan efisien & 4.45 & 4.25 & Negatif & 0,20 & Tidak Puas \\
\hline & $\begin{array}{l}\text { 14. Layanan yang diberikan sesuai dengan } \\
\text { yang djjagjikan }\end{array}$ & 4.42 & 4.17 & Negatif & 0,25 & Tidak Puas \\
\hline & $\begin{array}{l}\text { 15. Manajemen dan Staff profesional } \\
\text { dalam melayani }\end{array}$ & 4.18 & 4.45 & Positif & 0,27 & Puas \\
\hline \multirow{5}{*}{ 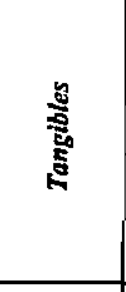 } & 16. Tampilan kantor yang menarik & 4.53 & 3.76 & Negatif & 0,77 & Tidak Puas \\
\hline & 17. Memiliki peralatan yang modem & 4.56 & 4.6 & Positif & $-0,04$ & Puas \\
\hline & 18. Sarana parkir memadai & 3.96 & 4.51 & Positif & 0,55 & Puas \\
\hline & $\begin{array}{l}\text { 19. Penampilan karyawan rapi dan } \\
\text { menarik }\end{array}$ & 4.16 & 4.66 & Positif & 0,50 & Puas \\
\hline & $\begin{array}{l}\text { 20. Tersedia fasilitas ruang tunggu yang } \\
\text { nyaman }\end{array}$ & 4.61 & 4.02 & Negatif & 0,59 & Tidak Puas \\
\hline \multirow{5}{*}{ 疍 } & 21. Lokasi kantor mudah djjangkau & 4.63 & 4.41 & Negatif & 0,22 & Tidak Puas \\
\hline & \begin{tabular}{|l|} 
22. \\
$\begin{array}{l}\text { Perhatian individual tanpa } \\
\text { membedakan status }\end{array}$ \\
\end{tabular} & 4.00 & 4.47 & Positif & 0,47 & Puas \\
\hline & $\begin{array}{l}\text { 23. Jam operasional sesuai kebutuhan } \\
\text { nasabah }\end{array}$ & 4.07 & 4.30 & Positif & 0,23 & Puas \\
\hline & 24. Menyediakan konsultasi keuangan & 4.32 & 3.73 & Negatif & 0,59 & Tidak Puas \\
\hline & $\begin{array}{l}\text { 25. Memberikan informasi mengenai } \\
\text { perubahan kebijakan }\end{array}$ & 4.44 & 4.21 & Negatif & 0,23 & Tidak Puas \\
\hline \multirow{5}{*}{ 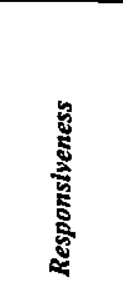 } & \begin{tabular}{|l|} 
26. Bersedia membantu konsumen jika ada \\
kesulitan
\end{tabular} & 4.17 & 4.46 & Positif & 0,29 & Puas \\
\hline & $\begin{array}{l}\text { 27. Karyawan melayani dengan sungguh - } \\
\text { sungguh }\end{array}$ & 4.16 & 4.39 & Positif & 0,23 & Puas \\
\hline & 28. Peganganan komplain cepat & 4.42 & 4.08 & Negatif & 0,34 & Tidak Puas \\
\hline & $\begin{array}{l}\text { 29. Dapat menyelesaikan masalah yang } \\
\text { dihadapi nasabah } \\
\end{array}$ & 4.41 & 4.07 & Negatif & 0,34 & Tidak Puas \\
\hline & 30. Prosedur administratif mudah & 4.41 & 4.14 & Negatif & 0,27 & Tidak Puas \\
\hline
\end{tabular}


Apabila dilihat berdasar atribut yang ada, nasabah BTN KCS Yogyakarta sudah merasa puas terhadap layanan yang diberikan pada atribut ; prinsip dan hukum Islam, tidak adanya pembayaran bunga tabungan, pemberian pembiayaan pada produk yang halal, reputasi dan nama baik BTN Syariah, karyawan sopan dan bersahabat, ketersediaan likuiditas, tersedianya tenaga keamanan, layanan yang cepat, Manajemen dan Staff yang profesional, layanan yang tepat, peralatan yang modern, sarana parkir, penampilan karyawan, perhatian individual, jam operasional, ketersediaan staff membantu konsumen, dan layanan karyawan sungguh - sungguh.

Sedangkan atribut yang belum dirasakan memuaskan bagi nasabah adalah tentang bunga pinjaman, agunan, pengalaman manajemen, produk dan layanan, layanan cepat dan efisien, layanan yang sesuai janji, tampilan kantor, fasilitas ruang tunggu, lokasi kantor, konsultasi keuangan, informasi mengenai perubahan kebijakan, penanganan komplain, penyelesaian masalah dan prosedur administratif.

\section{- Analisis Diagram Cartesius}

Gambar IDiagram Cartesius Rata - Rata Harapan dan Persepsi Kualitas LayananBTN KCS YogyakartaPer Dimensi

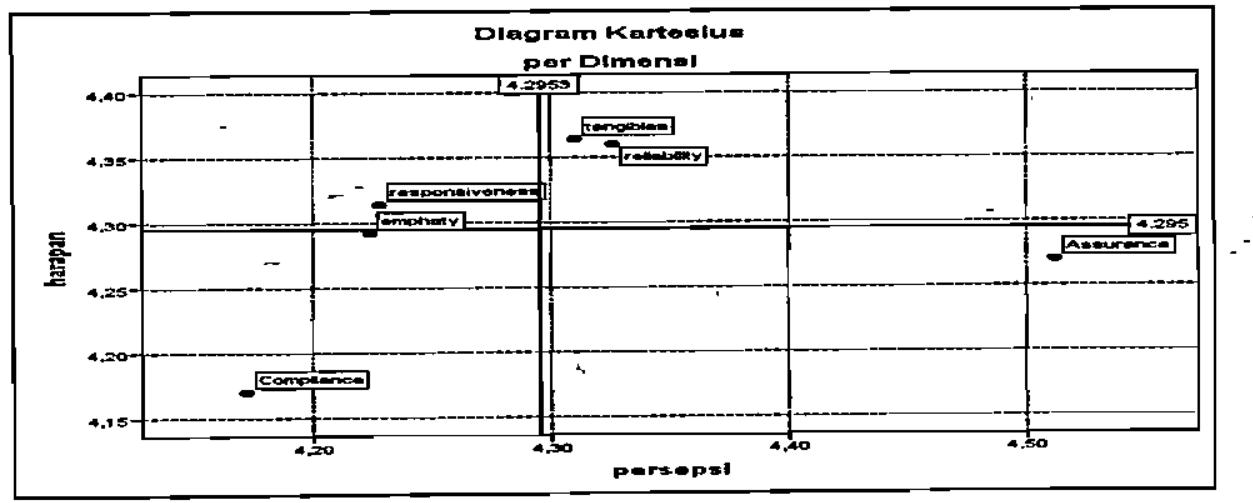

Sumber : hasil pengolahan data 
Gambar 2Diagram Cartesius Rata - Rata Harapan dan Persepsi Kualitas LayananBTN KCS Yogyakarta

Per Atribut

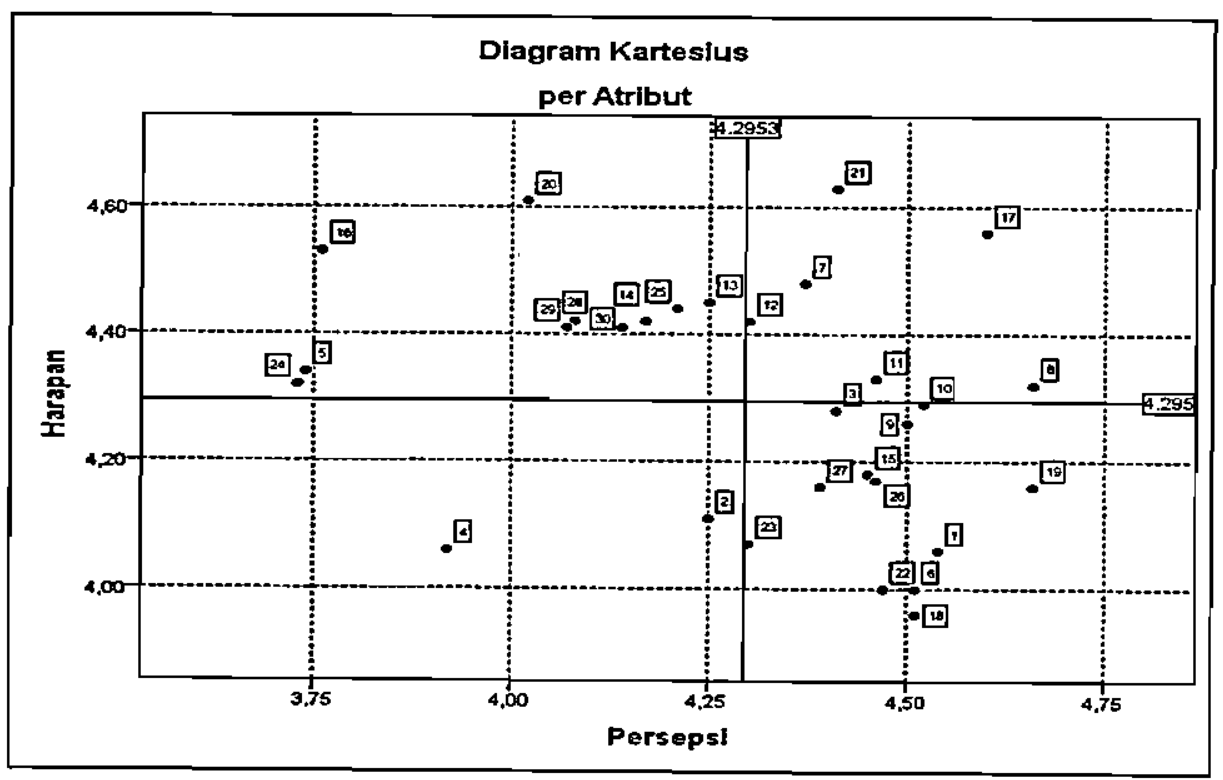

Diagram Cartesius mengelompokkan dimensi dan atribut yang ada menjadi empat kuadran, yaitu kuadran A, B, C dan D. Kuadran A (prioritas utama) menunjukkan dimensi dan atribut yang dianggap penting oleh nasabah, namun belum dijalankan dengan baik oleh manajemen. Kuadran B (pertahankan prestasi) menunjukkan unsur yang telah berhasil dijalankan dengan baik oleh perusahaan. Kuadran C (prioritas rendah) menunjukkan unsur yang dianggap kurang penting bagi nasabah dan pelaksanaannya - biasa - biasa saja oleh ${ }^{-}$perusahaan. Kuadran D (berlebihan) menunjukkan faktor yang oleh nasabah dianggap kurang penting namun dilakukan secara berlebihan oleh perusahaan.

Adapun interpretasi dari Diagram Cartesius tersebut dapat dijelaskan sebagai berikut : 


\section{Kuadran $\mathbf{A}$}

Atribut yang ada pada kuadran ini berarti atribut tersebut dinilai penting oleh nasabah, tapi pelaksanaannya dinilai masih kurang. Atribut atribut tersebut adalah ; tampilan kantor yang menarik (atribut 5), layanan yang cepat dan efisien (atribut 13), layanan yang diberikan sesuai dengan yang dijanjikan (atribut 14), tidak meminta agunan pada nasabah (atribut 16), tersedia fasilitas ruang tunggu yang nyaman (atribut 20), menyediakan konsultasi keuangan (atribut 24), memberikan informasi mengenai perubahan kebijakan (atribut 25), penanganan komplain cepat (atribut 28), dapat menyelesaikan masalah yang dihadapi nasabah (atribut 29) dan prosedur administratif mudah (atribut 30).

\section{Kuadran B}

Pada kuadran B, nilai kinerja tinggi dan kepentingan/harapan nasabah juga tinggi. Atribut-atribut yang berada pada kuadran ini berarti atribut tersebut dianggap penting oleh nasabah dan sudah dilaksanakan dengan baik oleh perusahaan. Atribut yang ada pada kuadran ini adalah ; manajemen memiliki pengalaman dan pengetahuan luas (atribut 7), karyawan sopan dan bersahabat (atribut 8), memberikan layanan yang tepat (atribut 11), produk dan layanan beragam (atribut 12), memiliki peralatan yang modern (atribut 17) dan lokasi kantor mudah dijangkau (atribut 21).

\section{Kuadran C}

Atribut yang ada pada kuadran $\mathrm{C}$, artinya dinilai kurang penting oleh nasabah dan oleh perusahaan atribut - atribut ini juga dilaksanakan dengan prioritas rendah. Atribut-atribut tersebut adalah ; tidak ada pembayaran bunga tabungan (atribut 2) dan menerapkan ketentuan bebas bunga pinjaman (atribut 4). 


\section{Kuadran D}

Pada kuadran D, atribut- atribut yang ada dianggap tidak terlalu penting namun dilaksanakan dengan baik oleh bank. Atribut-atribut tersebut adalah ; prinsip dan hukum Islam (atribut 1), memberikan pembiayaan pada produk yang halal (atribut 3), memiliki reputasi dan nama baik (atribut 6), ketersediaan likuiditas (atribut 9), tersedia tenaga keamanan(atribut 10), Manajemen dan Staff profesional dalam melayani (atribut 15), sarana parkir memadai (atribut 18), penampilan karyawan rapi dan menarik (atribut 19), perhatian individual tanpa membedakan status (atribut 22), jam operasional sesuai kebutuhan nasabah (atribut 23), bersedia membantu konsumen jika ada kesulitan (atribut 26), dan karyawan melayani dengan sungguh - sungguh (atribut 27).

\section{Kesimpulandan Saran}

\section{Kesimpulan}

1. Dari hasil analisis deskriptif yang dilakukan diperoleh total rata - rata kinerja (persepsi) sebesar 4.2593 dan harapan sebesar 4.2590. Total gap menunjukkan hasil positif sebesar 0.0003 yang artinya secara keseluruhan kualitas layanan yang diberikan oleh BTN KCS Yogyakarta selama ini sudah memuaskan nasabah.

2.- Berdasar dimensi yang ada, compliance dan assurance merupakan dimensi yang sudah memuaskan nasabah, sedangkan yang dirasabelum memuaskan nasabah adalah dimensi reliability, tangibles, emphaty dan responsiveness.

3. Atribut yang telah memuaskan nasabah, yaitu ; prinsip dan hukum Islam, tidak adanya pembayaran bunga tabungan, pemberian pembiayaan pada produk yang halal, réputási dan nama baik BTN 
Syariah, karyawan sopan dan bersahabat, ketersediaan likuiditas, tersedianya tenaga keamanan, layanan yang cepat, Manajemen dan Staff yang profesional, layanan yang tepat, peralatan yang modern, sarana parkir, penampilan karyawan, perhatian individual, jam operasional, ketersediaan staff membantu konsumen, dan layanan karyawan sungguh - sungguh.

4. Atribut yang belum memuaskan nasabah yaitu ; bunga pinjaman, agunan, pengalaman manajemen, produk dan layanan, layanan cepat dan efisien, layanan yang sesuai janji, tampilan kantor, fasilitas ruang tunggu, lokasi kantor, konsultasi keuangan, informasi mengenai perubahan kebijakan, penanganan komplain, penyelesaian masalah dan prosedur administratif.

\section{Saran}

1. BTN KCS Yogyakarta perlu meningkatkan kualitas layanan untuk atribut ; tampilan kantor yang menarik, layanan yang cepat dan efisien, layanan yang diberikan sesuai dengan yang dijanjikan, tidak meminta agunan pada nasabah, tersedia fasilitas ruang tunggu yang nyaman, menyediakan konsultasi keuangan, memberikan informasi mengenai perubahan kebijakan, penanganan komplain cepat, dapat menyelesaikan masalah yang dihadapi nasabah, dan prosedur administratif mudah. Hal ini dikarenakan atribut - atribut tersebut dianggap penting oleh nasabah namun belum dilaksanakan dengan baik oleh BTN KCS Yogyakarta.

2. Kualitas layanan yang telah dilaksanakan untuk atribut ; manajemen yang memiliki pengalaman dan pengetahuan luas, karyawan yang sopan dan bersahabat, memberikan layanan yang tepat, produk dan layanan beragam, memiliki peralatan yang modern, dan lokasi kantor 
mudah dijangkauharus dipertahankan, karena adalah atribut - atribut tersebut dianggap penting oleh nasabah dan sudah dilaksanakan dengan baik oleh BTN KCS Yogyakarta.

3. Untuk atribut ; tidak ada pembayaran bunga tabungan dan penerapan ketentuan bebas bunga pinjaman walaupun tidak dianggap penting oleh nasabah, kualitas layanan tetap harus ditingkatkan untuk menjaga kepuasan nasabah.

4. Atribut ; prinsip dan hukum Islam, memberikan pembiayaan pada produk yang halal, memiliki reputasi dan nama baik, ketersediaan likuiditas, tersedia tenaga keamanan, Manajemen dan Staff profesional, sarana parkir memadai, penampilan karyawan rapi dan menarik, perhatian individual tanpa membedakan status, jam operasional sesuai kebutuhan nasabah, bersedia membantu konsumen jika ada kesulitan, dan karyawan yang melayani dengan sungguh sungguhadalah atribut yang dianggap tidak penting namun telah dilaksanakan dengan baik oleh BTN KCS Yogyakarta. Untuk menjaga kepuasan nasabah, kualitas layanan untuk atribut - atribut tersebut tetap harus dipertahankan. 


\section{DAFTAR PUSTAKA}

Antonio, Muhammad Syafi'i.2000. Bank Syariah, dari Teori ke Praktek. Jakarta: Tazkia Institute.

Indrianto dkk. 1999. Metodologi Penelitian Bisnis untuk Akuntansi dan Manajemen. BPFE: Yogyakarta

Kotler, Phillip.2003.Marketing Management : Analysis, Planning, Implementation, and Control, 9th ed. Englewood Cliffs, NJ: Prentice-Hall,Inc.

Mulyanto, Erika Edi.2010. Pengaruh Kualitas Pelayanan TerhadapKepuasan Nasabah BTN SyariahCabang Yogyakarta. Tesis: Universitas Islam Indonesia. Yogyakarta.

Osman, et al. 2009.Customers Satisfaction in Malaysian Islamic Banking: Journal of Economics and Finance February, Vol 1 (1).

Othman, A. \& Owen, L.2002.The Multi Dimensionality of CARTER Models to Measure Customer Service Quality in Islamic Banking Industry: a Study in Kuwait Finance House. International Journal of Islamic Financial Services Vol3(4).

Othman, A. and Owen, L. 2001, "Developing an Instrument to Measure Customer Service Quality (SQ) in Islamic Banks", International Journal of Islamic Financial Services, Vol. 3 (1), Apriland June, pp. 1-26.

Parasuraman, et. al. 1988, "SERVQUAL: a multi-item scale for measuringconsumer perceptions of $S Q$ " : Journal of Retailing, Vol. 64.

Parasuraman, A., Berry, L., and Zeithaml, V. 1991.Perceived Service Quality as aCustomer - based Performance Measure: An Empirical Examination ofOrganizational Barries Using an Extended Service Quality Model. HumanResource management, Vol. 30 No. 3.

Supranto, Johanes.2001.Statistik Teori dan Aplikasi.Erlangga: Jakarta Thompson, DeSouza dan Gale. 1985. The Strategic Manegement of Services Quality. Cambridge, Massachusetts: Strategic Planning Institute.

Tjiptono, Fandy. 1996. Pemasaran Jasa. Penerbit Andi: Yogyakarta.

Tjiptono, Fandy dan gregorius, Chandra. 2005. Service Quality Satisfabtion. Penerbit Andi: Yogyakarta. 